\title{
Fingerprinting the sources of water-mobilized sediment threatening agricultural and water resource sustainability: Progress, challenges and prospects in China
}

\author{
Qiang TANG ${ }^{1,2}$, Bojie $\mathrm{FU}^{3,4}$, Anbang $\mathrm{WEN}^{2}$, Xinbao ZHANG ${ }^{2}$, \\ Xiubin $\mathrm{HE}^{2^{*}} \&$ Adrian L. COLLINS ${ }^{1 \dagger}$ \\ ${ }^{1}$ Sustainable Agriculture Sciences Department, Rothamsted Research, North Wyke, Okehampton, Devon EX20 2SB, UK; \\ ${ }^{2}$ Key Laboratory of Mountain Surface Processes and Ecological Regulation, Institute of Mountain Hazards and Environment, \\ Chinese Academy of Sciences, Chengdu 610041, China; \\ ${ }^{3}$ State Key Laboratory of Urban and Regional Ecology, Research Center for Eco-Environmental Sciences, \\ Chinese Academy of Sciences, Beijing 100085, China; \\ ${ }^{4}$ State Key Laboratory of Earth Surface Processes and Resource Ecology, Faculty of Geographical Science, \\ Beijing Normal University, Beijing 100875, China
}

Received November 12, 2018; revised March 20, 2019; accepted March 26, 2019; published online May 16, 2019

\begin{abstract}
Sediment source fingerprinting apportions the sources of sediment produced by water erosion by linking sampled sediment mixtures and landscape source materials using diagnostic and conservative fingerprints. Using this approach, the nature and location of active sediment sources across the catchment can be elucidated, generating information which is a key prerequisite for the design and implementation of catchment management strategies. The science of sediment source fingerprinting continues to attract much research globally, but to date, there have been relatively few fingerprinting studies in China. Here, there remain major challenges for the fingerprinting approach arising from the uniqueness of Chinese landscapes, including for instance, the complex land use configuration with highly fragmented or mosaic patches and the highly dynamic land use conversion rates, generating a need to test the physical basis for the discriminatory power and environmental behavior of both traditional and novel tracers. Future research is needed to investigate the applicability of tracer properties in different physiographic settings and to evaluate the potential strategic utility of the approach for supporting the improved management of soil and water sustainability. Here, the strategic availability of independent observation data for different components of catchment sediment budgets and well-maintained research infrastructure for plots, micro-catchments and drainage basins provides immediate opportunity for testing the approach and refining procedures. Such detailed testing across scales would be invaluable for promoting sediment source fingerprinting as both a scientific and management tool for informing soil and water conservation practices in China.
\end{abstract}

Keywords Soil erosion, Sediment source fingerprinting, Tracer properties, Sediment budgets, Catchment management, China

Citation: Tang Q, Fu B, Wen A, Zhang X, He X, Collins A L. 2019. Fingerprinting the sources of water-mobilized sediment threatening agricultural and water resource sustainability: Progress, challenges and prospects in China. Science China Earth Sciences, 62: 2017-2030, https://doi.org/10.1007/s11430018-9349-0

* Corresponding author (email: xiubinh@imde.ac.cn)

$\dagger$ Corresponding author (email: adrian.collins@rothamsted.ac.uk) 


\section{Introduction}

Soil represents an important natural resource and a key component of terrestrial ecosystems; providing habitats for organisms and supplying many ecosystem services (Barrios, 2007; Wagg et al., 2014). There is an increasing global recognition that soil erosion by water generates many on-site and off-site negative environmental consequences. Soil erosion, even though its magnitude is not always easily observable visually, contributes to continuous in-situ loss of fertile topsoil, nutrients and organic matter. The resultant land degradation raises a grand challenge for global sustainable agricultural production (Pimentel et al., 1995). Soil erosion alters the pristine physical, chemical and microbiological attributes of soils, thus perturbing hydrological and biogeochemical processes and degrading soil's capacity in sustaining valuable ecosystem services (Lal, 2003). The eroded sediment delivered to streams and rivers supports essential intrinsic structural and functional components of fluvial channels and aquatic ecosystems (Apitz, 2012). However, excessive sediment loads may cause significant channel adjustment, water quality deterioration and aquatic ecosystem degradation (Walling and Fang, 2003). High levels of fine-grained sediment increase water treatment costs, reduce light penetration and aquatic primary productivity, and act as a vector for the dispersal of nutrients and other pollutants (e.g., inorganic toxic elements, organic compounds) (Walling and Owens, 2003; Smith and Blake, 2014). Fluvial channel sedimentation destroys water infrastructure and reduces the operational capacity of dams.

Targeted uptake of management practices is critical for successful erosion mitigation and sediment control. Here, reliable sediment source information is a key prerequisite. A variety of conventional monitoring and measurement techniques has been deployed to quantify soil erosion and sediment redistribution rates at different spatial and temporal scales (Collins and Walling, 2004). Rates of soil erosion on hillslopes and the fluxes of suspended sediment at catchment scales are measured independently, however, giving rise to challenges in the linking of these datasets for estimation of source-specific load contributions and sediment budgeting. This is primarily because measuring, estimating or modelling intervening sediment delivery ratios is difficult. Sediment source fingerprinting avoids such practical problems by linking sediment outputs directly to landscape sources using a composite set of diagnostic fingerprint properties for source discrimination and quantifying the proportional contributions of each prescribed source category. Source-specific load contributions can be estimated by integrating source fingerprinting and sediment load data. Sediment source fingerprinting has been the focus of an increasing volume of research and has been widely applied globally over recent time. Despite this, its application in China is at an early stage even though soil erosion and excessive sediment yields are recognized as an overwhelming environmental challenge threatening agricultural and water resource sustainability. The fingerprinting approach offers potential for answering scientific enquiries on soil erosion and sediment dynamics and for informing the targeting of soil and water conservation measures. Accordingly, in this paper, we synthesize the progress of sediment source fingerprinting investigations both globally and more specifically in China. China comprises unique landscape features and complications arising from a long history of human disturbance. The site-specific nature of sediment source fingerprinting requires detailed testing of the principal methodological steps associated with the approach to ensure that reliable and accurate source estimates are obtained. Prospects for promoting the use of sediment source fingerprinting as a reliable scientific and management tool in China are explored.

\section{A brief review of the science of sediment source fingerprinting}

\subsection{Development history}

A large body of literature has documented the technological evolution and application of sediment source fingerprinting globally (Collins and Walling, 2004; Walling, 2005; Davis and Fox, 2009; Krishnappan et al., 2009; D'Haen et al., 2012; Guzmán et al., 2013; Haddadchi et al., 2013; Smith et al., 2013; Taylor et al., 2013; Walling, 2013; Mabit et al., 2014; Owens et al., 2016; Reiffarth et al., 2016; Upadhayay et al., 2017). The science of sediment source fingerprinting emerged in the 1970s (Klages and Hsieh, 1975; Walling et al., 1979), with the development of composite fingerprinting since the 1990s representing a key milestone (Collins et al., 1997a; Collins and Walling, 2002; Collins et al., 2012). Early studies explored the application of the fingerprinting approach in different environmental settings around the world. More recent work has re-visited many of the principal methodological assumptions and explored the implications for the robustness and accuracy of the source estimates generated (Koiter et al., 2013; Reiffarth et al., 2016; Laceby et al., 2017; Pulley et al., 2017b). Sediment fingerprinting approach has attracted expanding interest driven by increasing recognition of the environmental significance of fine-grained sediment and the urgent need to target management measures, and this is reflected by a rapid growth in the number of scientific publications (Koiter et al., 2013; Walling, 2013). The growing body of literature focuses on either methodological assessment and refinement by testing critical assumptions (e.g., source classification, fingerprint property behavior, uncertainty, mixing model optimization), or reports case study applications in various environments for scientific and management (e.g., identifying critical 
source for targeting control measures, re-evaluating managed sites and assessing conservation efficacy) purposes (Tiecher et al., 2018).

\subsection{Methodological basis}

Sediment source fingerprinting links catchment sediment outputs to landscape sources by assuming fingerprint properties with both conservative and diagnostic behavior reflect soil erosion and sediment delivery and thereby provide a basis for quantifying the relative source contributions by simulating the physical mixing of source fingerprint signatures using mass balance models. Two key stages are involved: (1) Source discrimination using composite signatures, and (2) source apportionment using mixing models. The discrimination stage uses various tracer properties to develop an optimized set of diagnostic tracers (i.e., a composite signature) for distinguishing individual sources (Walling, 2005; Koiter et al., 2013; Collins et al., 2017). These signatures are typically composite in nature since the use of a single property cannot resolve contributions from multiple sources. Inclusion of tracers preferably responding to differing environmental controls improves the robustness of source fingerprints. Here, whilst statistical solutions are always used for the confirmation of composite signatures, it is advisable to examine the physical basis for the source discrimination afforded by different properties. The numer- ical modelling assumes that the relative contributions from the individual sources can be estimated using a mathematical mixing model coupled with uncertainty analysis and that variations in sediment properties directly reflect spatial and temporal variations in the contributions of sediment eroded from the distinguishable sources and delivered to the sampled receptor. The approach treats various sediment transport processes as a black-box concept and in doing so, uses simple tests to confirm that tracer properties are broadly conservative and stable, with no major alterations in their concentrations or forms during the various phases of sediment mobilization and storage which are intermediate between erosion at various points in the landscape and sediment export at the downstream catchment outlet (Koiter et al., 2013).

Both the physical environment and human agents play a dual role in imprinting distinguishable fingerprints on different source materials and controlling sediment supply and redistribution at different spatial and temporal scales (Figure 1). Natural environments imprint the intrinsic signatures of soils. Consequently, the natural properties of eroded sediment can differ considerably on the basis of sediment origin and various physical, geochemical and biochemical properties have been widely utilized successfully as tracers (Koiter et al., 2013). Human practices have substantial impacts on sediment dynamics by disturbing soil structure (e.g., tillage), through seasonal variations in protective vegetation cover (e.

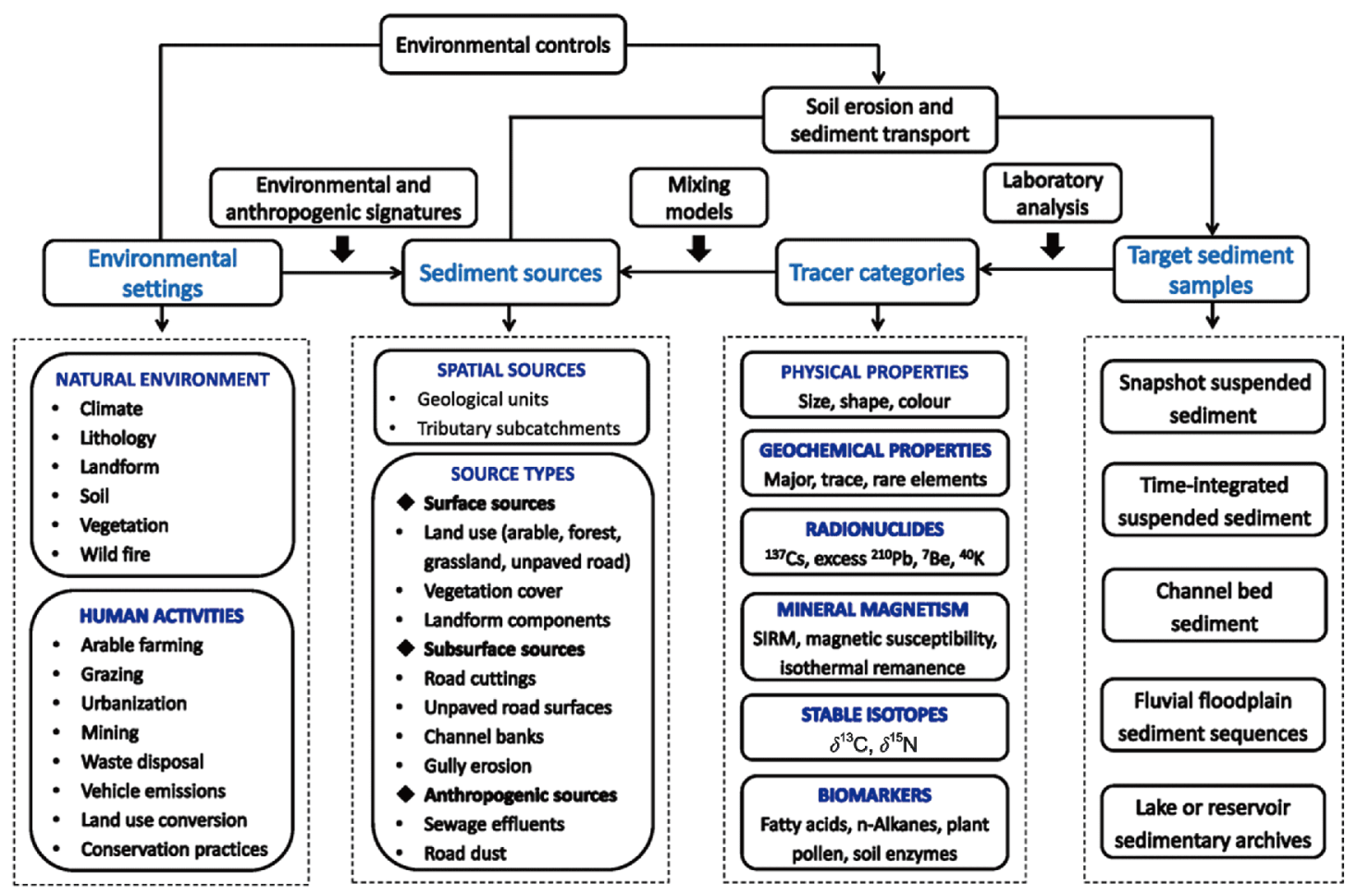

Figure 1 Natural and anthropogenic agents play a dual role in imparting source signatures and governing catchment soil erosion and sediment dynamics, which, in turn, affords a basis for using tracer properties to discriminate and apportion source contributions to target sediment samples collected in the river channel or from long-term sedimentary units including floodplains, lakes or reservoirs. 
g., in conjunction with different crops and their associated drilling and harvesting dates), and by changing slope to channel connectivity (e.g. due to road construction and river crossings, or artificial land drainage to support productive farming).

The general work flow in applying sediment source fingerprinting comprises several key sequential steps (Figure 2): Field walking, mapping and confirmation of potential sediment source groupings for rationalizing the catchment sampling strategy, field sampling of source materials and target sediment, laboratory analyses for preselected tracers, statistical tests for selection of diagnostic properties and confirmation of discriminatory power, use of multivariate mixing models potentially incorporating correction factors or weightings (Collins et al., 2010) and uncertainty analysis to estimate the relative contributions from the individual sources, goodness-of-fit (GOF) (Collins et al., 2012) and model accuracy tests using either artificial (Brosinsky et al., 2014) or virtual sediment mixtures (Palazón et al., 2015) and final interpretation of the results on the basis of the need for them to make environmental sense for the study area.

\subsection{Source classification}

Classification of potential source categories is frequently undertaken a priori, on the basis of field walking and mapping of erosion areas with clear connectivity to the sampled receptor (e.g., river channel network), but both previous and recent work has underscored the need to explore source classification schemes carefully to ensure a good fit with the tracers used and source samples retrieved from the field (Walling et al., 1993; Pulley and Collins, 2018). A priori source classification has commonly been based on either spatial sources (Nosrati et al., 2018a) subdivided by geological units (van der Waal et al., 2015) or tributary subcatchments (Theuring et al., 2015; Zebracki et al., 2015), or source types comprising surface and subsurface sources (Collins and Walling, 2004). Here, sediment produced from surface sources is of topsoil origin and is mobilized by processes including splash, sheet wash, and rilling (Figure 1) (Walling, 2013), while that mobilized from subsurface sources originates due to processes including bank erosion, gullying and mass failure (Collins and Walling, 2004). Since the surface source category is widespread spatially, it can be further discriminated by land use, vegetation type or landform. Anthropogenic sources include sewage effluent (e.g. from point source treatment works) or road dust (Figure 1). Most studies prescribe catchment sources based on source types rather than spatial units, since estimating contributions by source types provides more detailed information for targeting remediation. Source apportionment using tributary sub-catchment spatial sources can, however, be compared with monitored sediment loads at sub-catchment river gauges (Collins and Walling, 2004).

The classification of potential sources depends largely on the geographical environment of the study area and the

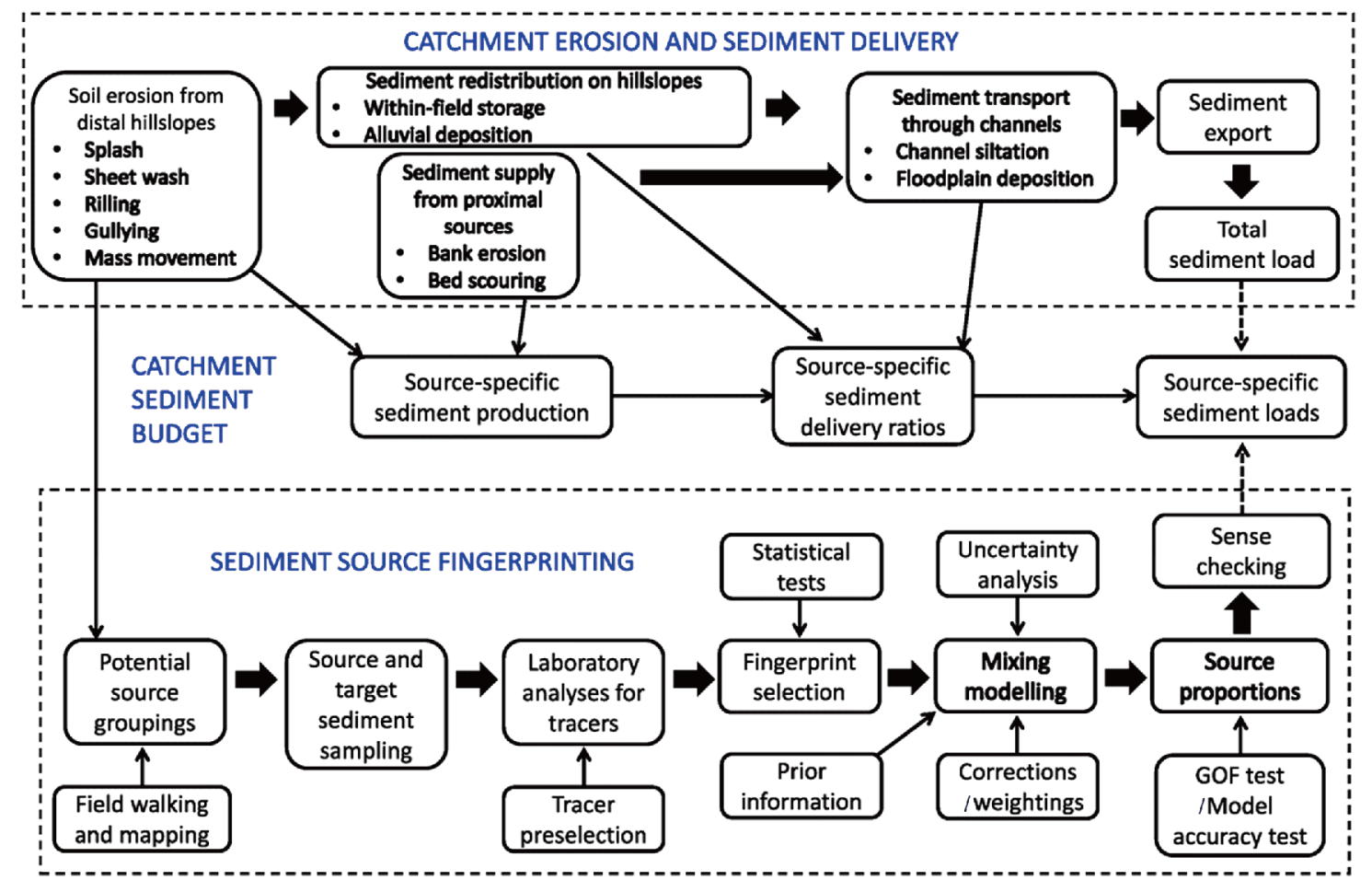

Figure 2 Quantifying the proportional contributions of individual catchment sources to target sediment samples using environmentally-relevant tracers. 
purpose of the work. The use of inappropriate source groups for the tracers selected may cause significant uncertainty for source estimation and thereby fail to address the research or management questions reliably. For example, overly broad source classification typically results in high within-source spatial heterogeneity, relative to between-source variability, and thereby hampers accurate determination of sources for targeting management (Owens et al., 2016). Recent studies underscore that comparing and selecting appropriate source group classification schemes is important for the accuracy of source estimates (Pulley et al., 2017a).

\subsection{Fingerprint properties}

The diversity of fingerprint properties has expanded continuously, representing an important methodological development of the fingerprinting approach driven by the expansion in the range of sources that need to be discriminated and recent advances in analytical capabilities (Walling, 2013), such as mid-, near-infrared and ultraviolet visible spectroscopy (Reeves and Smith, 2009; MartínezCarreras et al., 2016). To date, common tracer properties applied in fingerprinting studies include physical properties (e.g., particle size, density and color) (Martínez-Carreras et al., 2010; Erskine, 2013; Barthod et al., 2015), geochemical constituents (e.g., major, minor, rare earth elements) (Theuring et al., 2015), geogenic (e.g., ${ }^{40} \mathrm{~K},{ }^{238} \mathrm{U},{ }^{232} \mathrm{Th}$ ) radionuclides, fallout (e.g., ${ }^{137} \mathrm{Cs}$, excess ${ }^{210} \mathrm{~Pb},{ }^{7} \mathrm{Be}$ ) radionuclides (Shala et al., 2017), mineral magnetism (Rowntree et al., 2017), bulk stable isotopes (e.g., $\delta^{13} \mathrm{C}, \delta^{15} \mathrm{~N}$ ) (Parnell et al., 2010; McCarney-Castle et al., 2017), and biomarkers (e.g., fatty acids, n-alkanes) (Reiffarth et al., 2016; Upadhayay et al., 2017). Fallout radionuclides have been widely adopted to trace sediment redistribution based on the principles of comparing inventories rather than to apportion sediment source using tracer concentrations (Walling and Quine, 1990). The recent application of biomarkers in fingerprinting studies has potentially improved the capacity to discriminate sources with specific vegetation (Bravo-Linares et al., 2018) or crop types (Mabit et al., 2018), although there remains scope for further testing the environmental behavior and conservation of such tracers.

The methodological assumptions for sediment source fingerprinting require that any tracer properties employed as fingerprints should have two key features; namely, conservative and diagnostic behavior (Rose et al., 2018). The assumption of conservative behavior requires that fingerprint properties must remain broadly conserved during sediment mobilization, transport and deposition processes, without substantial chemical alteration or biological transformation, or that where such change occurs, it is predictable and measurable. This fundamental assumption ensures that fingerprints can be directly compared between individual sources and target sediment samples and used as input data within the numerical models used to estimate proportional contributions (Motha et al., 2002). The assumption for diagnostic characteristics focuses on the potential of fingerprint properties to provide greater between-source than within-source variability and thus homogeneity for any given source. Prevailing natural and anthropogenic processes govern fingerprints for different sources (Figure 1).

Over time, sediment source fingerprinting has evolved from using one single sediment property to discriminate two sources to establishing composite fingerprints comprising several properties preferably from a variety of property types (Figure 1), to discriminate an increasing number of sources and improve the accuracy of source estimations (Collins et al., 1997a; Collins and Walling, 2002). Numerous statistical tests have been applied to identify composite fingerprints and to increase the rigor of composite fingerprint selection by confirming the ability of the individual constituent properties to discriminate between the potential sources in question. Here, there is a need, nevertheless, to examine the physical reasoning for discrimination between sources rather than relying solely on statistical solutions. Property selection in different composite signatures can greatly affect the estimated source contributions and the corresponding accuracy (Zhang and Liu, 2016). Here, the choice of properties for generating different composite fingerprints depends largely on the nature of the sources to be discriminated and apportioned.

\subsection{Mass balance models and uncertainty analysis}

Use of un-mixing models to apportion target sediment samples between sources represents a key methodological development in source fingerprinting procedures over the past 25-30 years (Walling, 2013). Explicit assessment of uncertainty during the application of un-mixing models was first introduced in the form of Monte Carlo analysis (Rowan et al., 2000). Such analysis has shown that the ranges in uncertainty for the source apportionment estimates is largely a product of the within-source group variability in tracer concentrations and the corresponding differences in tracer concentrations between-source groups. Consequently, variability ratios (of inter-/intra-source group variability) have been recommended to capture the fundamental need to select tracers that maximize between- rather than withingroup tracer variation (Pulley et al., 2015b). These ratios should be applied as an initial screen in the tracer selection procedure (Collins and Walling, 2002). Other work has also proposed distribution-based modelling, to ensure that multiple model iterations for uncertainty analyses maintain relationships between tracers to reduce the uncertainty ranges for apportionment estimates (Laceby and Olley, 2015).

A growing body of recent research has compared varia- 
tions in source apportionment using different un-mixing models (Haddadchi et al., 2014; Nosrati et al., 2018b) and here researchers can select either maximum likelihood/frequentist or Bayesian approaches. Beyond that initial choice, researchers also need to assess, on the basis of the tracer data for their study catchment, the appropriateness of different model structures in terms of including or excluding a range of corrections and weightings for factors including particle size and organic matter selectivity which can influence the comparability of source and target sediment tracer concentrations (Smith and Blake, 2014; Laceby and Olley, 2015; Collins et al., 2017).

\subsection{The growing diversity of target sediment samples}

The temporal resolution and duration of sediment source fingerprinting studies depends on how the target sediment samples are collected (Figure 1). To date, a wide range of target sediment samples has been used, including storm event-based snapshot (Navratil et al., 2012) or time-integrated suspended sediment samples (Smith and Blake, 2014), fluvial floodplain deposits (Collins et al., 1997b; van der Waal et al., 2015), and core samples of lake or reservoir sedimentary archives (Palazón et al., 2014). Extension of the temporal coverage of the sediment data from single events to decades allows for evaluation of the long-term effect of natural and anthropogenic controls on sediment dynamics. Accordingly, different sampling strategies are used to collect different types of target sediment samples, including snapshot sampling and filtration (Dutton et al., 2013), portable centrifugation, time-integrating passive samplers (Phillips et al., 2000) or basket traps (Collins et al., 2014) and the coring of floodplain, lake or reservoir sedimentary archives (Owens et al., 1999; Pulley et al., 2015a; Lintern et al., 2016).

\section{Progress of sediment source fingerprinting studies in China}

Globally, an important distinction can be made between studies tracing soil erosion and sediment redistribution along hillslope hydrological continuums and the fingerprinting of catchment sediment sources, even though both approaches share the use of tracers to elucidate soil erosion and sediment dynamics at different spatial and temporal scales (Parsons and Foster, 2011; Koiter et al., 2013; Taylor et al., 2013; Mabit et al., 2014; Owens et al., 2016). To date, and especially since the 1990s, many tracing investigations have been carried out in China, where soil properties and, specifically fallout radionuclides (e.g., ${ }^{137} \mathrm{Cs},{ }^{210} \mathrm{~Pb}$ ex and ${ }^{7} \mathrm{Be}$ ), have been preselected to quantify soil redistribution rates on catchment hillslopes (Zhang et al., 1990; Zhang et al., 1998; Zhang et al., 2003; Yang et al., 2006; Shi et al., 2013; Li et al., 2015).
Additionally, abundant results have also been generated by the dating of sedimentary archives and reconstruction of long-term historical sediment and associated pollution dynamics for various sediment sinks (e.g., ponds, check-dams and reservoirs) (Yan et al., 2002; Zhang et al., 2007; Bai et al., 2013; Zhao et al., 2017b). In contrast, however, the use of sediment source fingerprinting is at an early stage in China and its progress is far behind that of the rest of the global research community. The few existing studies have mainly focused on using fingerprinting to quantify sediment source contributions in several typical landscapes, but the methodological robustness and accuracy of the estimates obtained remain untested and warrant further attention. Here, we summarize these scientific outputs based on the specific geographical environments in question (Table 1).

The Loess Plateau is a hot-spot area for soil erosion and thereby a management priority for targeting conservation measures. Accordingly, most studies using the source fingerprinting approach have been undertaken here. Local landforms generally comprise gullies and inter-gully slopes, representing two contrasting geomorphological components of a fragile landscape with different degrees of vegetation cover and contrasting erosion features. The gullied areas are characterized by deep-cut valleys and steep walls with sparse vegetation, with mass failure prevailing in the forms of head cuts and gully wall collapse. In contrast, the inter-gully areas comprise consecutive slopes with diverse land use and vegetation cover, including woodland, shrubs, grassland, dry farmland and orchards. Soil erosion on these hillslopes is dominated by splash, sheet wash, and rilling. By classifying gullied and inter-gully hillslopes as subsurface and surface sources, respectively, particle size (Wang, 2001) and ${ }^{137} \mathrm{Cs}$ (Wen et al., 1998) have been successfully applied to quantify their relative contributions as distinct sediment sources to sediment yield, with gully erosion identified as the major contributor. Other studies further divided the inter-gully slopes by land use and obtained consistent source estimates indicating that farmland and gullying are the two major sources. Here, geochemical fingerprinting was used to apportion land use-based sources for storm-event sediment samples (Zhang et al., 2017b), and for check-dam deposits (Chen et al., 2016b). Two studies established composite fingerprints comprising properties from different tracer groups to discriminate sources for check-dam deposits (Zhao et al., 2017a) and for sediment samples collected during a single storm event (Yang and $\mathrm{Xu}, 2010$ ). More recent studies have used biomarker tracers (e.g., n-alkanes, stable isotopes) to apportion the sources of sediment-associated organic matter in check dams (Chen et al., 2016a; Chen et al., 2017; Liu et al., 2018). The presence of pollen in soil is a direct consequence of inputs from the overlying vegetation, and this can also provide an effective basis for distinguishing different sediment sources. This type of sediment finger- 


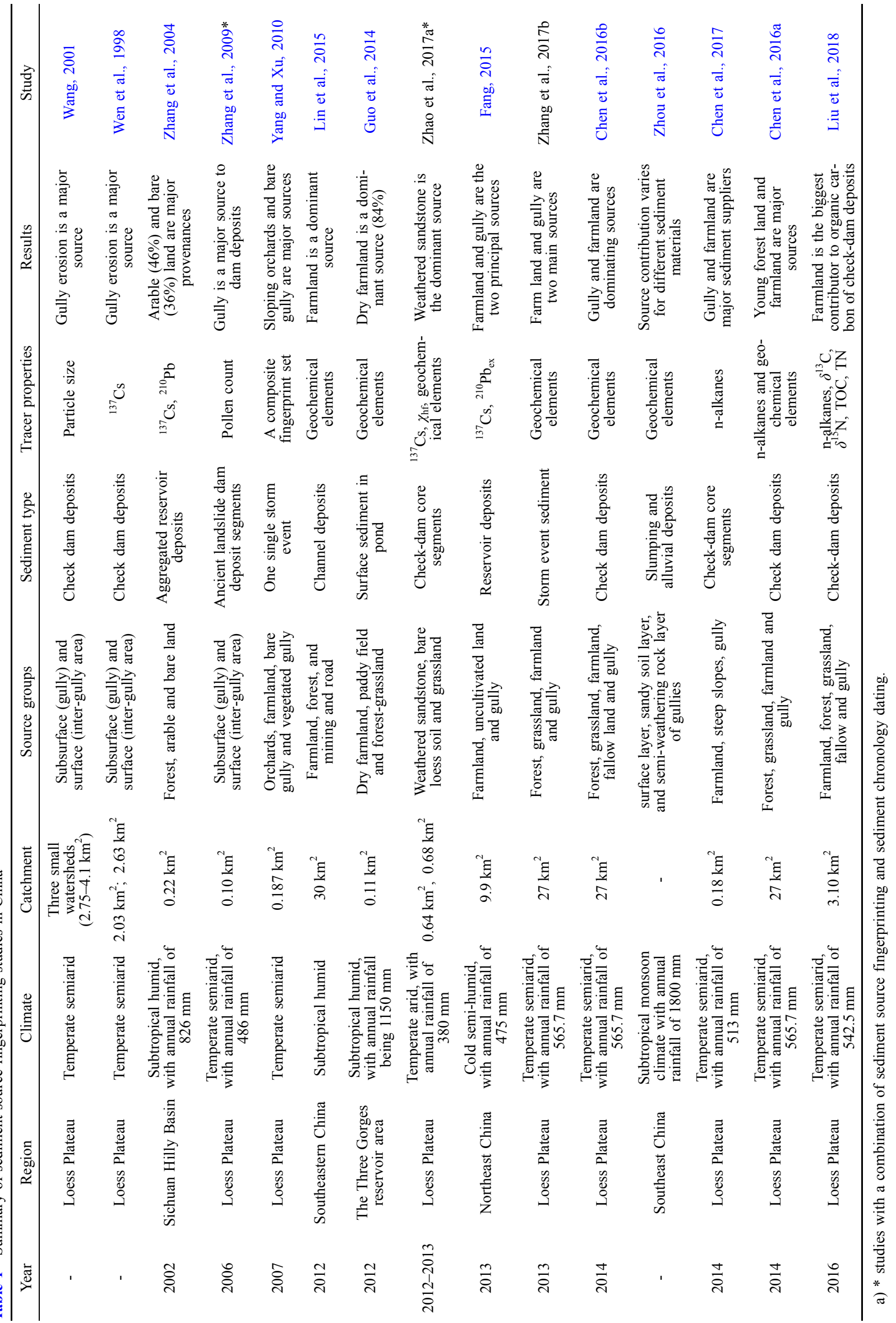


printing has been employed to infer, qualitatively, the sources of sedimentary archives retrieved from an ancient landslide dam on the Loess Plateau (Zhang et al., 2009).

The upper Yangtze River basin represents another critical area for soil erosion assessment and its improved management. Here, the combined use of ${ }^{137} \mathrm{Cs}$ and ${ }^{210} \mathrm{~Pb}_{\text {ex }}$ as fingerprints in a small watershed in the Sichuan Hilly basin suggested that farmland and bare land are the two principal sediment sources for sediment samples collected from a downstream reservoir (Zhang et al., 2004). A combination of ${ }^{137} \mathrm{Cs}$ and ${ }^{210} \mathrm{~Pb}_{\mathrm{ex}}$ was also applied to quantify sediment source contributions for reservoir sediment cores in a study area in northeast China with a cold climate (Fang, 2015). Geochemical fingerprinting carried out in a small catchment in the Three Gorges Reservoir Area suggested that dry farmland was a principal sediment source (Guo et al., 2014).

There are two existing case studies from southeastern China using composite geochemical fingerprinting. One was undertaken to quantify the contributions of different horizons of gully walls to slumping and alluvial deposits with different gully conditions (i.e., active, potentially stable and stale) in Fujian (Lin et al., 2015), whilst the other study was carried out in a small catchment with mixed land use in Jiangsu (Zhou et al., 2016).

\section{Major generic challenges for, and methodo- logical gaps in, using sediment fingerprinting in Chinese landscapes}

Given the highly site-specific nature of sediment source fingerprinting, the global research community has found it challenging to formulate an all-encompassing protocol guiding the application of the approach in any physio-geographic setting. Some recent reviews have, however, proposed general decision-trees to help guide end-users through critical steps in applying the approach robustly (Collins et al., 2017; Laceby et al., 2017). Here, it is important to note that individual steps remain under scrutiny or further development (Pulley et al., 2017b) and decision-trees are therefore likely to evolve further as scientific consensus is reached. There remain important challenges derived from the uniqueness of landscapes in China and the complicated history of human interference. These challenges have the potential to undermine the robustness of the fingerprinting technique, thus leading to enhanced uncertainties and inaccuracies. In this section, we therefore briefly summarize generic challenges related to applying sediment source fingerprinting in Chinese landscapes. We also summarize gaps in the existing application or testing of methodological steps for state-ofthe-art application of source tracing in China, by benchmarking the recent case studies against the latest decisiontrees for the global research and end-user community.

\subsection{Fragmented landscape configuration and frequent land use change}

Agriculture in China is mainly run by households and smallholders meaning that land use patterns are highly fragmented and subject to frequent transformation. Both these characteristics pose important challenges for using some tracer properties since the signal-to-noise ratios can be distorted. For this reason, it is vitally important to consider carefully the physical basis for source discrimination using specific tracers and the likelihood of complications resulting from prevailing natural and anthropogenic controls. The fragmented nature of sediment sources in Chinese landscapes also has implications for the numbers of source samples required and this, in turn, has important implications for logistics, costs and accuracy (Clarke and Minella, 2016; Collins et al., 2017). Successful allocation of sediment sources in the large river basins characteristic of China depends largely on the prescribed sources being classified in a meaningful manner for the tracers applied and on those sources being adequately represented by the collection of sufficient sample numbers. Here, within-source spatial homogeneity requires careful consideration. Spatially-representative sampling may be achieved by using a stratified approach and weighting on the basis of soil erosion rates in catchments with a large gradient of such rates (Wilkinson et al., 2015). Frequent land use change is likely to pose a challenge for applying biomarkers deterministic of specific vegetation families as distinctive signatures will become obscured. Given these complexities, a confluence-based sampling strategy designed to apportion the relative contributions from spatial sources (i.e. individual tributary subcatchments) may provide the most pragmatic means of applying sediment fingerprinting in the largest drainage basins.

\subsection{Under-explored potential sediment sources}

Human-derived sediment sources represent an important component of landscapes in China due to large-scale infrastructure expansion in the context of population growth and economic development. Such infrastructure projects and urban areas can generate sediment fluxes several orders of magnitude higher than those from natural landscapes, yet the role of active construction sites as sediment sources has been rarely studied (Voli et al., 2013). Identification of the most suitable tracers for helping to distinguish construction sites in Chinese landscapes warrants further research.

\subsection{Problems for unlocking sedimentary archives}

China has many lakes and artificial reservoirs of varying sizes. The undisturbed sedimentary archives in these land- 
scape features potentially provides a basis for retrospective studies of historical sediment dynamics and sources using sediment profile dating and stratigraphic fingerprinting. A major challenge here, however, involves the conservative behaviour of fingerprint properties in the sedimentary archive post deposition and the potential for non-conservatism to distort the match between the fingerprint properties of contemporary source samples and historical sediment. Where the reservoir has a large catchment area, additional challenges will include rationalizing source groups, and the time, labour and financial resources required to collect sufficiently robust sample numbers. Nevertheless, unlocking the long-term sediment source information in more sedimentary archives offers the potential to establish strategic baseline data for assessing the impacts of different soil conservation strategies across China. This application of source tracing therefore warrants further attention since the use of sedimentary archives overcomes the absence of long-term conventional river monitoring for observing changes in response to large-scale sustainability programmes.

\subsection{Tracer pre-selection and corresponding analytical capability}

Currently, there remains a lack of standardized procedures and advice for fingerprint property pre-selection. This results in the need to collect large sample masses to permit the measurement of more types of tracers and significant analytical time and costs. The availability of analytical instruments may be a limitation for the use of specific sediment tracers for applying sediment fingerprinting in many research institutions in China. A strategic programme of research is therefore needed to address the knowledge gap associated with tracer pre-selection for different environments. Such research should use the widespread bounded erosion plot and instrumented micro-catchment facilities across China (e.g., Golosov et al., 2017) to explore the conservatism of different tracers at nested scales in contrasting environmental settings.

\subsection{Benchmarking recent case studies against state-of- the-art decision trees}

Table 2 benchmarks recent case study applications of source tracing in China against critical steps in recent methodological decision trees (e.g., Collins et al., 2017). The methodological steps most frequently addressed or openly reported in the recent case studies in China concern clarifying the physical basis for tracer selection, the application of tracer conservatism tests, confirmation of the logic for mixing model structure and the use of GOF tests. Those methodological steps never or the least applied or openly reported in the recent case studies in China concern selection of an ap- propriate particle size fraction for the target sediment and tracers used, using tracer variability ratios, assessment of the potential benefits of source group re-classification, use of independent statistical tests to identify $>1$ final composite signature and testing the accuracy of model predictions with either artificial or virtual sediment mixtures (Table 2).

\section{Prospects for sediment source fingerprinting as a scientific and management tool in China}

\subsection{Evolution of the soil erosion and sediment problem and reactive management in China}

Accelerated soil erosion and resulting elevated suspended sediment fluxes have been widely documented for river catchments in China since the 1950s (Yang et al., 2004; Zhang et al., 2006; Zhao et al., 2014). Human activities are highly influential factors for soil erosion, and the extent and intensity of human impacts have been closely related to social activities. During the first Five-Year Plan and Great Leap Forward campaign in the 1950s, large areas of natural forest were harvested, and land was reclaimed for addressing increased demand for food, fuel and fiber. From the late 1970s, launch of the Household Land Responsibility Scheme empowered local farmers to make free decisions on farming activities on their land, which greatly motivated farmers to make full use of their land area. A direct consequence was that land use intensity increased with an expansion of mechanized ploughing and power harrowing. This expansion of intensive agriculture and reduction in forested area magnified regional soil erosion rates and fluvial suspended sediment fluxes, threatening agricultural and water resource sustainability (Wei et al., 2011).

Since the late 1980s, multiple national conservation campaigns have been successively carried out to promote erosion mitigation and ecosystem restoration. A comprehensive soil conversation scheme emerged in 1988 to install numerous conservation measures (e.g., conservation tillage, terracing and construction of sedimentary ponds and reservoirs) at selected demonstration catchments. The implementation of this programme has been expanded greatly with continued government investments. A national forest preservation scheme was initiated in 1998 to launch a ban on logging and to protect natural forest from continuing destruction. In 1999, a national reforestation scheme - the "grain-for-green" programme, was also introduced to restore forest cover through the provision of financial subsidies to local famers for returning farmland on steep hillslopes to native forest.

Since 2000, China has accelerated its pace in dam construction to claim the multiple benefits of hydropower development, flood control and water supply. Cascade dam complexes have been proposed on China's 13 major rivers (Zhang et al., 2017a). Meanwhile, China's rural economy has 
Tang Q, et al. $\quad$ Sci China Earth Sci $\quad$ December (2019) Vol.62 No.12

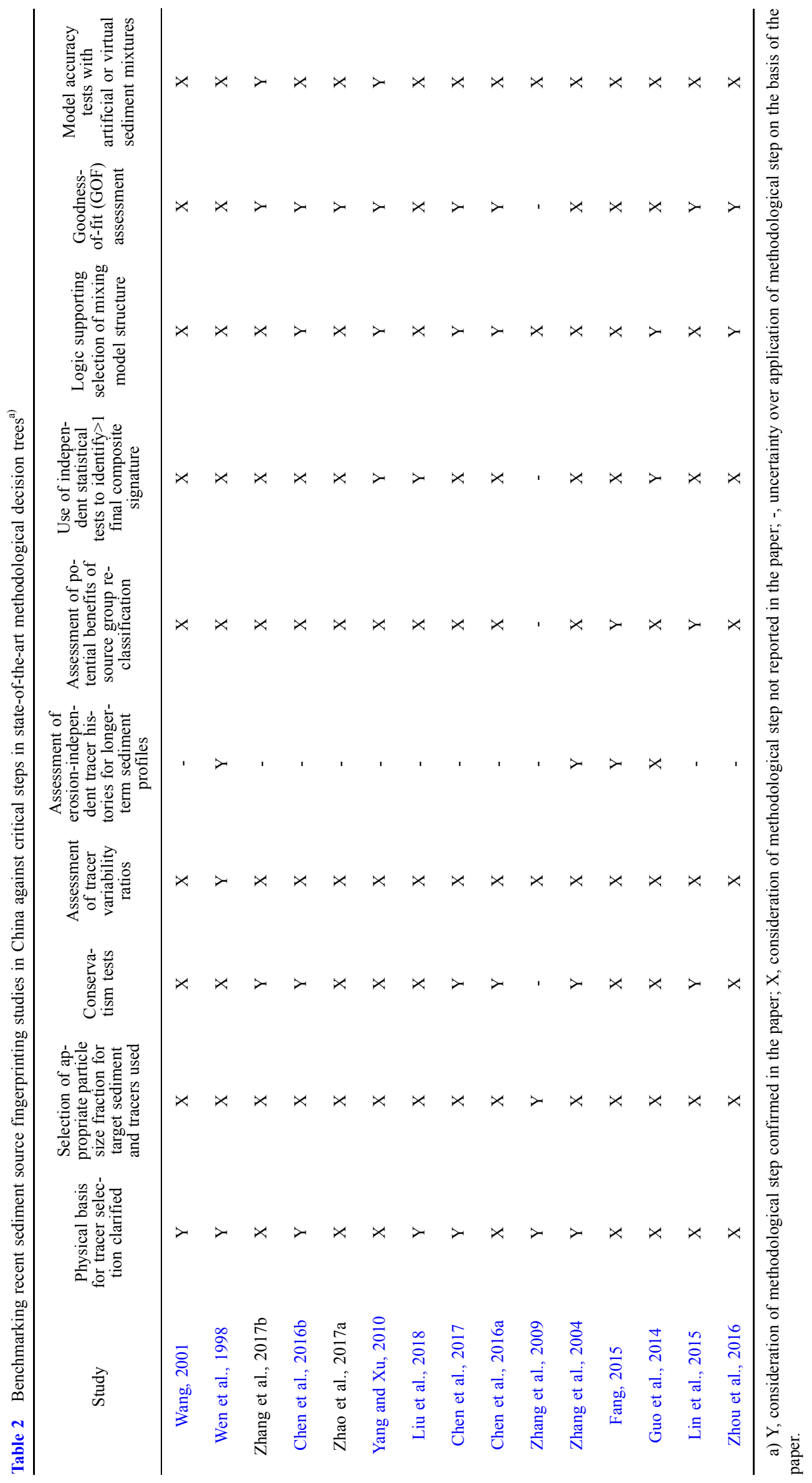




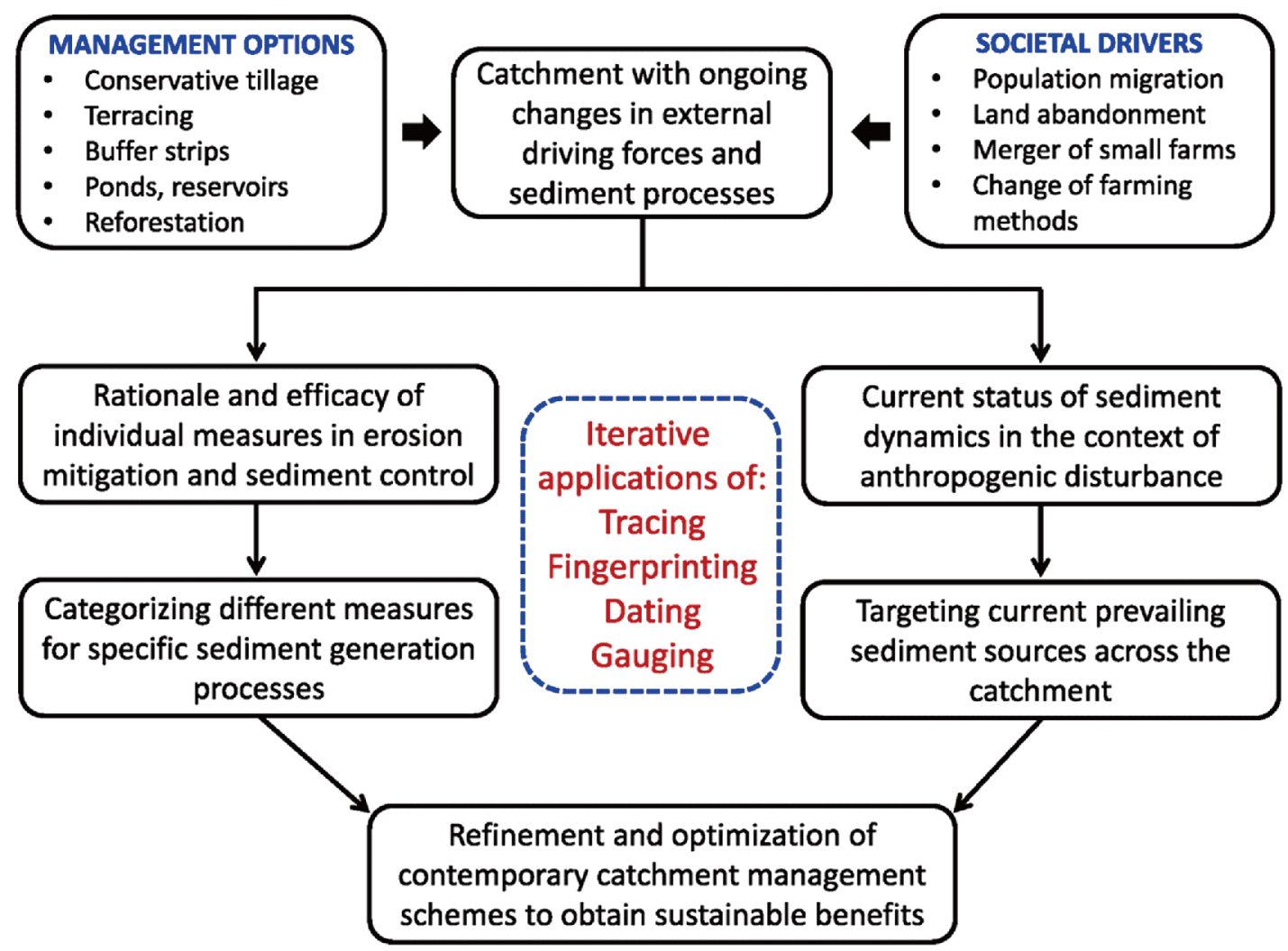

Figure 3 A schematic illustrating how sediment source fingerprinting and additional tools could be used iteratively for evaluating the underpinning rationale and effectiveness of targeted soil and water conservation measures.

experienced substantial changes with large areas of farmland being abandoned following the migration of the rural population to rapidly expanding cities. At the same time, agriculture is shifting from small-sized household-based farming units to large-scale commercial farming enterprises. All these changes will undoubtedly exert impacts in terms of farming methods and land use intensity, and ultimately on catchment soil erosion and sediment dynamics. Targeted applications of the fingerprinting approach can be used to document the impacts of such change in China.

5.2 Growing scientific and practical interests in the collection of reliable data to target management of the soil erosion and sediment problems in China

In the context of the above, many studies have been conducted in China to evaluate the effectiveness of conservation campaigns, using, for example, remote sensing of vegetation cover improvements at national or regional scales, intervention modelling, or by measuring long-term trends in fluvial hydro-sedimentological data (Wang et al., 2016; Yang et al., 2018). But it remains challenging to determine the specific impacts of conservation strategies using such approaches. Sediment source fingerprinting is capable of explicitly formulating the rationale for, and of assessing the effectiveness of, conservation practices targeted at specific spatial locations for erosion control and sediment mitigation. Wider application of sediment fingerprinting in China could therefore provide the knowledge for assisting adjustment and optimization of current, or the design of new, management strategies (i.e., precision conservation) (Figure 3). However, before widespread uptake becomes a reality, the many methodological assumptions of sediment source fingerprinting need to be tested more rigorously in the context of the contrasting geographical environments across China. Here, wider uptake would also be assisted by consensus on various methodological steps in source fingerprinting procedures. Consensus would help standardize applications, improve the comparability of source tracing studies, clarify methodological requirements to new users and ensure the accuracy and reliability of the datasets generated for informing targeted management actions and assessment of their outcomes.

Acknowledgements This work was supported by a Royal Society Newton International Fellowship (Grant No. NF161415, awarded to Q Tang and supervised by A L Collins), the National Natural Science Foundation of China (Grant Nos. 41771320 \& 41771321), a UK Biotechnology and Biological Sciences Research Council (BBSRC) strategic programme (Grant No. BBS/E/C/000I0330 - Soil to Nutrition), the Chinese Academy of Sciences "Light of West China" programme (awarded to $Q$ Tang) and the President's International Fellowship Initiative (Grant No. 2018VCA0033, awarded to A L Collins). 


\section{References}

Apitz S E. 2012. Conceptualizing the role of sediment in sustaining ecosystem services: Sediment-ecosystem regional assessment (SEcoRA). Sci Total Environ, 415: 9-30

Bai X, Zhang X, Long Y, Liu X, Siyu Z. 2013. Use of ${ }^{137} \mathrm{Cs}$ and ${ }^{210} \mathrm{~Pb}_{\mathrm{ex}}$ measurements on deposits in a karst depression to study the erosional response of a small karst catchment in Southwest China to land-use change. Hydrol Process, 27: 822-829

Barrios E. 2007. Soil biota, ecosystem services and land productivity. Ecol Econ, 64: 269-285

Barthod L R M, Liu K, Lobb D A, Owens P N, Martínez-Carreras N, Koiter A J, Petticrew E L, McCullough G K, Liu C, Gaspar L. 2015. Selecting color-based tracers and classifying sediment sources in the assessment of sediment dynamics using sediment source fingerprinting. J Environ Qual, 44: 1605-1616

Bravo-Linares C, Schuller P, Castillo A, Ovando-Fuentealba L, MuñozArcos E, Alarcón O, de Los Santos-Villalobos S, Cardoso R, Muniz M, Meigikos Dos Anjos R, Bustamante-Ortega R, Dercon G. 2018. First use of a compound-specific stable isotope (CSSI) technique to trace sediment transport in upland forest catchments of Chile. Sci Total Environ, 618: 1114-1124

Brosinsky A, Foerster S, Segl K, Kaufmann H. 2014. Spectral fingerprinting: Sediment source discrimination and contribution modelling of artificial mixtures based on VNIR-SWIR spectral properties. J Soil Sediment, 14: 1949-1964

Chen F, Fang N, Shi Z. 2016a. Using biomarkers as fingerprint properties to identify sediment sources in a small catchment. Sci Total Environ, 557-558: 123-133

Chen F X, Fang N F, Wang Y X, Tong L S, Shi Z H. 2017. Biomarkers in sedimentary sequences: Indicators to track sediment sources over decadal timescales. Geomorphology, 278: 1-11

Chen F, Zhang F, Fang N, Shi Z. 2016b. Sediment source analysis using the fingerprinting method in a small catchment of the Loess Plateau, China. J Soil Sediment, 16: 1655-1669

Clarke R T, Minella J P G. 2016. Evaluating sampling efficiency when estimating sediment source contributions to suspended sediment in rivers by fingerprinting. Hydrol Process, 30: 3408-3419

Collins A L, Foster I D L, Gellis A C, Porto P, Horowitz A J. 2017. Sediment source fingerprinting for informing catchment management: Methodological approaches, problems and uncertainty. J Environ Manage, 194: 1-3

Collins A L, Walling D E. 2002. Selecting fingerprint properties for discriminating potential suspended sediment sources in river basins. J Hydrol, 261: 218-244

Collins A L, Walling D E. 2004. Documenting catchment suspended sediment sources: Problems, approaches and prospects. Prog Phys Geogr, 28: $159-196$

Collins A L, Walling D E, Leeks G J L. 1997a. Source type ascription for fluvial suspended sediment based on a quantitative composite fingerprinting technique. Catena, 29: 1-27

Collins A L, Walling D E, Leeks G J L. 1997b. Use of the geochemical record preserved in floodplain deposits to reconstruct recent changes in river basin sediment sources. Geomorphology, 19: 151-167

Collins A L, Walling D E, Webb L, King P. 2010. Apportioning catchment scale sediment sources using a modified composite fingerprinting technique incorporating property weightings and prior information. Geoderma, 155: 249-261

Collins A L, Williams L J, Zhang Y S, Marius M, Dungait J A J, Smallman D J, Dixon E R, Stringfellow A, Sear D A, Jones J I, Naden P S. 2014. Sources of sediment-bound organic matter infiltrating spawning gravels during the incubation and emergence life stages of salmonids. Agric EcoSyst Environ, 196: 76-93

Collins A L, Zhang Y, McChesney D, Walling D E, Haley S M, Smith P. 2012. Sediment source tracing in a lowland agricultural catchment in southern England using a modified procedure combining statistical analysis and numerical modelling. Sci Total Environ, 414: 301-317
D’Haen K, Verstraeten G, Degryse P. 2012. Fingerprinting historical fluvial sediment fluxes. Prog Phys Geogr, 36: 154-186

Davis C M, Fox J F. 2009. Sediment fingerprinting: Review of the method and future improvements for allocating nonpoint source pollution. J Environ Eng, 135: 490-504

Dutton C, Anisfeld S C, Ernstberger H. 2013. A novel sediment fingerprinting method using filtration: Application to the Mara River, East Africa. J Soil Sediment, 13: 1708-1723

Erskine W D. 2013. Soil colour as a tracer of sediment dispersion from erosion of forest roads in Chichester State Forest, NSW, Australia. Hydrol Process, 27: 933-942

Fang H. 2015. Temporal variations of sediment source from a reservoir catchment in the black soil region, Northeast China. Soil Tillage Res, 153: $59-65$

Golosov V, Collins A L, Tang Q, Zhang X, Zhou P, He X, Wen A. 2017. Sediment transfer at different spatial and temporal scales in the Sichuan Hilly Basin, China: Synthesizing data from multiple approaches and preliminary interpretation in the context of climatic and anthropogenic drivers. Sci Total Environ, 598: 319-329

Guo J, Wen A B, Yan D C, Shi Z L. 2014. Quantifying catchment scale sediment source using composite fingerprinting technique (in Chinese with English Abstract). T Chinese Soc Agr Eng, 30: 94-104

Guzmán G, Quinton J N, Nearing M A, Mabit L, Gómez J A. 2013. Sediment tracers in water erosion studies: Current approaches and challenges. J Soil Sediment, 13: 816-833

Haddadchi A, Olley J, Laceby P. 2014. Accuracy of mixing models in predicting sediment source contributions. Sci Total Environ, 497-498: $139-152$

Haddadchi A, Ryder D S, Evrard O, Olley J. 2013. Sediment fingerprinting in fluvial systems: Review of tracers, sediment sources and mixing models. Int J Sediment Res, 28: 560-578

Klages M G, Hsieh Y P. 1975. Suspended solids carried by the Gallatin River of southwestern Montana: II. Using mineralogy for inferring sources. J Environ Qual, 4: 68-73

Koiter A J, Owens P N, Petticrew E L, Lobb D A. 2013. The behavioural characteristics of sediment properties and their implications for sediment fingerprinting as an approach for identifying sediment sources in river basins. Earth-Sci Rev, 125: 24-42

Krishnappan B G, Chambers P A, Benoy G, Culp J. 2009. Sediment source identification: A review and a case study in some Canadian streams. Can J Civil Eng, 36: 1622-1633

Laceby J P, Evrard O, Smith H G, Blake W H, Olley J M, Minella J P G, Owens P N. 2017. The challenges and opportunities of addressing particle size effects in sediment source fingerprinting: A review. EarthSci Rev, 169: 85-103

Laceby J P, Olley J. 2015. An examination of geochemical modelling approaches to tracing sediment sources incorporating distribution mixing and elemental correlations. Hydrol Process, 29: 1669-1685

Lal R. 2003. Soil erosion and the global carbon budget. Environ Int, 29: $437-450$

Li Y, Chappell A, Nyamdavaa B, Yu H, Davaasuren D, Zoljargal K. 2015. Cost-effective sampling of ${ }^{137} \mathrm{Cs}$-derived net soil redistribution: Part 1 -Estimating the spatial mean across scales of variation. J Environ Radioact, 141: 97-105

Lin J, Huang Y, Wang M, Jiang F, Zhang X, Ge H. 2015. Assessing the sources of sediment transported in gully systems using a fingerprinting approach: An example from South-east China. Catena, 129: 9-17

Lintern A, Leahy P J, Zawadzki A, Gadd P, Heijnis H, Jacobsen G, Connor S, Deletic A, McCarthy D T. 2016. Sediment cores as archives of historical changes in floodplain lake hydrology. Sci Total Environ, 544: $1008-1019$

Liu C, Li Z, Chang X, Nie X, Liu L, Xiao H, Wang D, Peng H, Zeng G. 2018. Apportioning source of erosion-induced organic matter in the hilly-gully region of loess plateau in China: Insight from lipid biomarker and isotopic signature analysis. Sci Total Environ, 621: 13101319

Mabit L, Benmansour M, Abril J M, Walling D E, Meusburger K, Iurian A 
R, Bernard C, Tarján S, Owens P N, Blake W H, Alewell C. 2014. Fallout ${ }^{210} \mathrm{~Pb}$ as a soil and sediment tracer in catchment sediment budget investigations: A review. Earth-Sci Rev, 138: 335-351

Mabit L, Gibbs M, Mbaye M, Meusburger K, Toloza A, Resch C, Klik A, Swales A, Alewell C. 2018. Novel application of compound specific stable isotope (CSSI) techniques to investigate on-site sediment origins across arable fields. Geoderma, 316: 19-26

Martínez-Carreras N, Schwab M P, Klaus J, Hissler C. 2016. In situ and high frequency monitoring of suspended sediment properties using a spectrophotometric sensor. Hydrol Process, 30: 3533-3540

Martínez-Carreras N, Udelhoven T, Krein A, Gallart F, Iffly J F, Ziebel J, Hoffmann L, Pfister L, Walling D E. 2010. The use of sediment colour measured by diffuse reflectance spectrometry to determine sediment sources: Application to the Attert River catchment (Luxembourg). J Hydrol, 382: 49-63

McCarney-Castle K, Childress T M, Heaton C R. 2017. Sediment source identification and load prediction in a mixed-use Piedmont watershed, South Carolina. J Environ Manage, 185: 60-69

Motha J A, Wallbrink P J, Hairsine P B, Grayson R B. 2002. Tracer properties of eroded sediment and source material. Hydrol Process, 16: 1983-2000

Navratil O, Evrard O, Esteves M, Legout C, Ayrault S, Némery J, MateMarin A, Ahmadi M, Lefèvre I, Poirel A, Bonté P. 2012. Temporal variability of suspended sediment sources in an alpine catchment combining river/rainfall monitoring and sediment fingerprinting. Earth Surf Proc Land, 37: 828-846

Nosrati K, Collins A L, Madankan M. 2018a. Fingerprinting sub-basin spatial sediment sources using different multivariate statistical techniques and the Modified MixSIR model. Catena, 164: 32-43

Nosrati K, Haddadchi A, Collins A L, Jalali S, Zare M R. 2018b. Tracing sediment sources in a mountainous forest catchment under road construction in northern Iran: Comparison of Bayesian and frequentist approaches. Environ Sci Pollut Res, 25: 30979-30997

Owens P N, Blake W H, Gaspar L, Gateuille D, Koiter A J, Lobb D A, Petticrew E L, Reiffarth D G, Smith H G, Woodward J C. 2016. Fingerprinting and tracing the sources of soils and sediments: Earth and ocean science, geoarchaeological, forensic, and human health applications. Earth-Sci Rev, 162: 1-23

Owens P N, Walling D E, Leeks G J L. 1999. Use of floodplain sediment cores to investigate recent historical changes in overbank sedimentation rates and sediment sources in the catchment of the River Ouse, Yorkshire, UK. Catena, 36: 21-47

Palazón L, Gaspar L, Latorre B, Blake W H, Navas A. 2014. Evaluating the importance of surface soil contributions to reservoir sediment in alpine environments: A combined modelling and fingerprinting approach in the Posets-Maladeta Natural Park. Solid Earth, 5: 963-978

Palazón L, Latorre B, Gaspar L, Blake W H, Smith H G, Navas A. 2015. Comparing catchment sediment fingerprinting procedures using an auto-evaluation approach with virtual sample mixtures. Sci Total Environ, 532: 456-466

Parnell A C, Inger R, Bearhop S, Jackson A L. 2010. Source partitioning using stable isotopes: Coping with too much variation. Plos One, 5: e9672

Parsons A J, Foster I D L. 2011. What can we learn about soil erosion from the use of ${ }^{137} \mathrm{Cs}$ ? Earth-Sci Rev, 108: 101-113

Phillips J M, Russell M A, Walling D E. 2000. Time-integrated sampling of fluvial suspended sediment: A simple methodology for small catchments. Hydrol Process, 14: 2589-2602

Pimentel D, Harvey C, Resosudarmo P, Sinclair K, Kurz D, McNair M, Crist S, Shpritz L, Fitton L, Saffouri R, Blair R. 1995. Environmental and economic costs of soil erosion and conservation benefits. Science, 267: $1117-1123$

Pulley S, Collins A L. 2018. Tracing catchment fine sediment sources using the new SIFT (SedIment Fingerprinting Tool) open source software. Sci Total Environ, 635: 838-858

Pulley S, Foster I, Antunes P. 2015a. The application of sediment fingerprinting to floodplain and lake sediment cores: Assumptions and un- certainties evaluated through case studies in the Nene Basin, UK. J Soil Sediment, 15: 2132-2154

Pulley S, Foster I, Antunes P. 2015b. The uncertainties associated with sediment fingerprinting suspended and recently deposited fluvial sediment in the Nene river basin. Geomorphology, 228: 303-319

Pulley S, Foster I, Collins A L. 2017a. The impact of catchment source group classification on the accuracy of sediment fingerprinting outputs. J Environ Manage, 194: 16-26

Pulley S, Van Der Waal B, Collins A L, Foster I D L, Rowntree K. 2017 b. Are source groups always appropriate when sediment fingerprinting? The direct comparison of source and sediment samples as a methodological step. River Res Appl, 33: 1553-1563

Reeves J B, Smith D B. 2009. The potential of mid- and near-infrared diffuse reflectance spectroscopy for determining major- and trace-element concentrations in soils from a geochemical survey of North America. Appl Geochem, 24: 1472-1481

Reiffarth D G, Petticrew E L, Owens P N, Lobb D A. 2016. Sources of variability in fatty acid (FA) biomarkers in the application of compound-specific stable isotopes (CSSIs) to soil and sediment fingerprinting and tracing: A review. Sci Total Environ, 565: 8-27

Rose L A, Karwan D L, Aufdenkampe A K. 2018. Sediment fingerprinting suggests differential suspended particulate matter formation and transport processes across hydrologic regimes. J Geophys Res, 123: 12131229

Rowan J S, Goodwill P, Franks S W. 2000. Uncertainty estimation in fingerprinting suspended sediment sources. In: Foster I D L, ed. Tracers in Geomorphology. Chichester: Wiley. 279-290

Rowntree K M, van der Waal B W, Pulley S. 2017. Magnetic susceptibility as a simple tracer for fluvial sediment source ascription during storm events. J Environ Manage, 194: 54-62

Shala F, Xhixha M K, Hasani F, Xhixha G, Massa G, Khyabani F R, Xhixha E, Shyti M. 2017. Terrestrial and fallout radionuclide fingerprints of sediments from highway stormwater retention ponds. J Radioanal Nucl Chem, 313: 385-390

Shi Z, Wen A, Ju L, Yan D. 2013. A modified model for estimating soil redistribution on grassland by using ${ }^{7} \mathrm{Be}$ measurements. Plant Soil, 362 : 279-286

Smith H G, Blake W H. 2014. Sediment fingerprinting in agricultural catchments: A critical re-examination of source discrimination and data corrections. Geomorphology, 204: 177-191

Smith H G, Blake W H, Owens P N. 2013. Discriminating fine sediment sources and the application of sediment tracers in burned catchments: A review. Hydrol Process, 27: 943-958

Taylor A, Blake W H, Smith H G, Mabit L, Keith-Roach M J. 2013. Assumptions and challenges in the use of fallout beryllium-7 as a soil and sediment tracer in river basins. Earth-Sci Rev, 126: 85-95

Theuring P, Collins A L, Rode M. 2015. Source identification of finegrained suspended sediment in the Kharaa River basin, northern Mongolia. Sci Total Environ, 526: 77-87

Tiecher T, Minella J P G, Evrard O, Caner L, Merten G H, Capoane V, Didoné E J, dos Santos D R. 2018. Fingerprinting sediment sources in a large agricultural catchment under no-tillage in Southern Brazil (Conceição River). Land Degrad Dev, 29: 939-951

Upadhayay H R, Bodé S, Griepentrog M, Huygens D, Bajracharya R M, Blake W H, Dercon G, Mabit L, Gibbs M, Semmens B X, Stock B C, Cornelis W, Boeckx P. 2017. Methodological perspectives on the application of compound-specific stable isotope fingerprinting for sediment source apportionment. J Soil Sediment, 17: 1537-1553

van der Waal B, Rowntree K, Pulley S. 2015. Flood bench chronology and sediment source tracing in the upper Thina catchment, South Africa: The role of transformed landscape connectivity. J Soil Sediment, 15: 2398-2411

Voli M T, Wegmann K W, Bohnenstiehl D W R, Leithold E, Osburn C L, Polyakov V. 2013. Fingerprinting the sources of suspended sediment delivery to a large municipal drinking water reservoir: Falls Lake, Neuse River, North Carolina, USA. J Soil Sediment, 13: 1692-1707

Wagg C, Bender S F, Widmer F, van der Heijden M G A. 2014. Soil 
biodiversity and soil community composition determine ecosystem multifunctionality. Proc Natl Acad Sci USA, 111: 5266-5270

Walling D E. 2005. Tracing suspended sediment sources in catchments and river systems. Sci Total Environ, 344: 159-184

Walling D E. 2013. The evolution of sediment source fingerprinting investigations in fluvial systems. J Soil Sediment, 13: 1658-1675

Walling D E, Fang D. 2003. Recent trends in the suspended sediment loads of the world's rivers. Glob Planet Change, 39: 111-126

Walling D E, Owens P N. 2003. The role of overbank floodplain sedimentation in catchment contaminant budgets. Hydrobiologia, 494: 83-91

Walling D E, Peart M R, Oldfield F, Thompson R. 1979. Suspended sediment sources identified by magnetic measurements. Nature, 281: 110113

Walling D E, Quine T A. 1990. Calibration of caesium-137 measurements to provide quantitative erosion rate data. Land Degrad Dev, 2: 161-175

Walling D E, Woodward J C, Nicholas A P. 1993. A multiparameter approach to fingerprinting suspended sediment sources. In: Peters $\mathrm{N} \mathrm{E}$, Hoehn E, Leibundgut C, Tase N, Walling D E, eds. Tracers in Hydrology. Wallingford: IAHS Publ. 215: 329-338

Wang S, Fu B, Piao S, Lü Y, Ciais P, Feng X, Wang Y. 2016. Reduced sediment transport in the Yellow River due to anthropogenic changes. Nat Geosci, 9: 38-41

Wang X. 2001. Tracing sediment sources in a Sandstone catchment using particle size analysis (in Chinese). Soil Water Conserv China, 1: 22-24

Wei J, He X, Bao Y. 2011. Anthropogenic impacts on suspended sediment load in the Upper Yangtze river. Reg Environ Change, 11: 857-868

Wen A B, Zhang X B, Walling D E. 1998. A study on soil erosion rates and sediment sources using caesium-137 technique in a small drainage of the Loess Hills (in Chinese with English Abstract). Acta Geogr Sin, 53: 124-133

Wilkinson S N, Olley J M, Furuichi T, Burton J, Kinsey-Henderson A E. 2015. Sediment source tracing with stratified sampling and weightings based on spatial gradients in soil erosion. J Soil Sediment, 15: 20382051

Yan P, Shi P, Gao S, Chen L, Zhang X, Bai L. 2002. ${ }^{137}$ Cs dating of lacustrine sediments and human impacts on Dalian Lake, Qinghai Province, China. Catena, 47: 91-99

Yang H F, Yang S L, Xu K H, Milliman J D, Wang H, Yang Z, Chen Z, Zhang C Y. 2018. Human impacts on sediment in the Yangtze River: A review and new perspectives. Glob Planet Change, 162: 8-17

Yang M Y, Tian J L, Liu P L. 2006. Investigating the spatial distribution of soil erosion and deposition in a small catchment on the Loess Plateau of China, using ${ }^{137} \mathrm{Cs}$. Soil Tillage Res, 87: 186-193

Yang M Y, Xu L J. 2010. Fingerprinting suspended sediment sources in a small catchment on the Loess Plateau (in Chinese with English Abstract). J Soil Water Conserv, 24: 30-34

Yang S L, Shi Z, Zhao H Y, Li P, Dai S B, Gao A. 2004. Effects of human activities on the Yangtze River suspended sediment flux into the estuary in the last century. Hydrol Earth Syst Sci, 8: 1210-1216
Zebracki M, Eyrolle-Boyer F, Evrard O, Claval D, Mourier B, Gairoard S, Cagnat X, Antonelli C. 2015. Tracing the origin of suspended sediment in a large Mediterranean river by combining continuous river monitoring and measurement of artificial and natural radionuclides. Sci Total Environ, 502: 122-132

Zhang D, Wang J, Lin Y, Si Y, Huang C, Yang J, Huang B, Li W. 2017a. Present situation and future prospect of renewable energy in China. Renew Sust Energy Rev, 76: 865-871

Zhang J, Yang M, Zhang F, Zhang W, Zhao T, Li Y. 2017b. Fingerprinting sediment sources after an extreme rainstorm event in a small catchment on the Loess Plateau, PR China. Land Degrad Develop, 28: 2527-2539

Zhang Q, Xu C, Becker S, Jiang T. 2006. Sediment and runoff changes in the Yangtze River basin during past 50 years. J Hydrol, 331: 511-523

Zhang X, Quine T A, Walling D E. 1998. Soil erosion rates on sloping cultivated land on the Loess Plateau near Ansai, Shaanxi Province, China: An investigation using ${ }^{137} \mathrm{Cs}$ and rill measurements. Hydrol Process, 12: 171-189

Zhang X, Walling D E, He X, Long Y. 2009. Use of landslide-dammed lake deposits and pollen tracing techniques to investigate the erosional response of a small drainage basin in the Loess Plateau, China, to land use change during the late 16th century. Catena, 79: 205-213

Zhang X, He X, Wen A, Walling D E, Feng M, Zhou X. 2004. Sediment source identification by using ${ }^{137} \mathrm{Cs}$ and ${ }^{210} \mathrm{~Pb}$ radionuclides in a small catchment of the Hilly Sichuan Basin, China. Chin Sci Bull, 49: 1953

Zhang X, Higgitt D L, Walling D E. 1990. A preliminary assessment of the potential for using caesium-137 to estimate rates of soil erosion in the Loess Plateau of China. Hydrol Sci J, 35: 243-252

Zhang X, Walling D E, Feng M Y. 2003. ${ }^{210} \mathrm{~Pb}_{\mathrm{ex}}$ depth distribution in soil and calibration models for assessment of soil erosion rates from ${ }^{210} \mathrm{~Pb}_{\mathrm{ex}}$ measurements. Chin Sci Bull, 48: 813

Zhang X B, Wen Z M, Feng M Y, Yang Q K, Zheng J J. 2007. Application of ${ }^{137} \mathrm{Cs}$ fingerprinting technique to interpreting sediment production records from reservoir deposits in a small catchment of the hilly loess plateau, China. Sci China Ser D-Earth Sci, 50: 254-260

Zhang X C J, Liu B L. 2016. Using multiple composite fingerprints to quantify fine sediment source contributions: A new direction. Geoderma, 268: 108-118

Zhao G, Mu X, Han M, An Z, Gao P, Sun W, Xu W. 2017a. Sediment yield and sources in dam-controlled watersheds on the northern Loess Plateau. Catena, 149: 110-119

Zhao G, Mu X, Strehmel A, Tian P. 2014. Temporal variation of streamflow, sediment load and their relationship in the Yellow River basin, China. Plos One, 9: e91048

Zhao T, Yang M, Walling D E, Zhang F, Zhang J. 2017b. Using check dam deposits to investigate recent changes in sediment yield in the Loess Plateau, China. Glob Planet Change, 152: 88-98

Zhou H, Chang W, Zhang L. 2016. Sediment sources in a small agricultural catchment: A composite fingerprinting approach based on the selection of potential sources. Geomorphology, 266: 11-19

(Responsible editor: Shilong PIAO)

Open Access This article is distributed under the terms of the Creative Commons Attribution 4.0 International License (http://creativecommons.org/licenses/ by/4.0/), which permits use, duplication, adaptation, distribution and reproduction in any medium or format, as long as you give appropriate credit to the original author(s) and the source, provide a link to the Creative Commons license and indicate if changes were made. 